\title{
Evaluation of the relationship between hyperemesis gravidarum with Platelet crit, hemoglobin to red cell distribution width ratio and Neutrophil to lymphocyte ratio
}

Kazım UÇKAN

Yusuf Başkıran ( $\nabla$ yusufbaskiran1@gmail.com )

Van Eğitim ve Araştırma Hastanesi: Van Egitim ve Arastirma Hastanesi https://orcid.org/0000-00031123-6062

Assistant Professor İzzet ÇELEĞEN

\section{Research Article}

Keywords: Hyperemesis gravidarum, Inflammation, PUQE, Platelet crit (PCT), Hemoglobin to red cell distribution width ratio (HRR), Neutrophil to lymphocyte ratio (NLR)

Posted Date: May 11th, 2022

DOI: https://doi.org/10.21203/rs.3.rs-1320179/v3

License: (c) (i) This work is licensed under a Creative Commons Attribution 4.0 International License. Read Full License 


\section{Abstract}

\section{Introduction:}

This study, it was aimed to investigate the relationship between the severity of hyperemesis gravidarum (HEG) disease and subclinical inflammatory factors such as Platelet crit (PCT), Hemoglobin to red cell distribution width ratio (HRR), Neutrophil to lymphocyte ratio (NLR), which are known to be closely associated with inflammation in patients with hyperemesis gravidarum.

Material method: This retrospective case control study was conducted between December 2020 and December 2021. A total of 215 pregnant women, 102 with hyperemesis gravidarum and 113 healthy pregnant women, were included in the study. HEG patients were divided into three groups according to the modified PUQE classification as mild $(n=38)$, moderate $(n=32)$, and severe $(n=32)$.

Results: PCT, HRR, and, NLR values were found to be statistically significantly higher in the HEG group compared to the control group $(p<0.05)$. PCT, HRR, and, NLR values increase from mild to severe in HEG patients $(p<0.05)$. There was a positive correlation between HEG and PCT (rho $=0.70, p<0.001), H R R$ $(r h o=0.28, p<0.04), N L R(r h o=0.60, p<0.001)$ values. Logistic regression analysis revealed that a oneunit increase in PCT, HRR, and NLR resulted in a 2.14, 1.41, and 2.36-fold increase in HEG risk, respectively.

Conclusion: PCT, HRR and NLR are inflammatory markers that increase in patients with HEG and have predictive value for the development of HEG. In our study, we suggested the use of a new prognostic marker for patients with HEG. We think that our study will be a source for future studies on HEG.

\section{Introduction}

Nausea and vomiting are common during pregnancy. It is an uncomfortable condition that most pregnant women experience with varying severity. It is among the most common causes of hospitalization in the first trimester of pregnancy [1]. While nausea and vomiting are common during pregnancy and are present in over $50 \%$ of pregnant women. HEG is relatively rare and occurs in only about $0.5 \%$ of pregnancies [2]. Hyperemesis gravidarum or pernicious vomiting of pregnancy affects between $0.3 \%$ and $2 \%$

of all pregnant patients [3]. In approximately $0.3-3 \%$ of pregnancies, hyperemesis gravidarum is prevalent and this percentage varies on account of different diagnostic criteria and ethnic variation in study populations [4]. Currently, there is no consensus on the definition of hyperemesis gravidarum (HEG; protracted vomiting in pregnancy) and no single widely used set of diagnostic criteria for HEG. The various definitions rely on symptoms, sometimes in combination with laboratory tests [5].

There are several possible mechanisms suggested being involved in the pathogenesis of HEG. Many different pathological conditions such as hormonal changes, immunological mechanisms, Helicobacter 
pylori infection, abnormal gastric motility, genetic predisposition, liver dysfunction have been counted [6]. The role of inflammation in the pathogenesis of HEG is not clear enough. In some studies, it is stated that there are important links between indicators of inflammation and HEG [7-8].

Although complete blood count $(\mathrm{CBC})$ is a simple and inexpensive method, it contains important parameters for the diagnosis of many diseases. While there are more expensive methods to evaluate the inflammatory process, white blood cell (WBC), platelet distribution width (PDW), mean platelet volume (MPV), red cell distribution width (RDW), neutrophil lymphocyte ratio (NLR), platelet lymphocyte ratio (PLR), and platelet crit (PCT) have been shown to reflect disease activity [9-10].

Neutrophils are a type of white blood cell that plays an important role in the body's protection and defense. Lymphocytes are another type of white blood cell that is very important in the formation of the body's immune response. Red cell distribution width (RDW) is a blood parameter that is measured depending on the distribution of erythrocytes over diameter or volume and has a close relationship with inflammatory factors [11]. Hemoglobin $(\mathrm{Hb})$ and RDW are markers derived from red blood cells. It has been reported that these two markers reflect inflammation and correlate with cancer prognosis [12-13]. In some cancers, $\mathrm{Hb}$ and RDW have each been shown to be prognostic on their own. There are limited studies on the HB/RDW (HRR) ratio, which is used as a very new marker. Studies on the HRR value were specially conducted on cancer patients [14].

The aim of this study is to investigate whether PCT and NLR, as well as HRR, which is a very new parameter that has never been studied in this disease, can be predictive parameters for the severity of Hyperemesis Gravidarum disease.

\section{Methods}

This retrospective case control study was conducted in the Gynecology and Obstetrics Unit of Van Training and Research Hospital. Data were obtained by examining the records of pregnant women hospitalized with the diagnosis of HEG between December 2020 and 2021. This study was conducted in line with the principles of the Declaration of Helsinki. Ethics committee approval was obtained for the study from the Van Ministry of Health University Training and Research Hospital Clinical Research and Ethics Committee with the decision number 2022/02-01 dated 18.01.2022. Verbal informed consent was obtained from all participants included in the study. A total of 213 pregnant women, including 102 pregnant women with hyperemesis gravidarum and 113 healthy pregnant women between 5-16 weeks of age, were included in the study.

The following criteria were used for the diagnosis of HEG:

1. Weight loss of $5 \%$ or more since the beginning of pregnancy

2. Vomiting at least three times a day

3. A ketonuria value of +1 or higher on a urinalysis test; 
The Pregnancy Unique Quantification of Emesis/Stomach (PUQE) scoring system was used to determine severity. The PUQE score was calculated by adding the scores of the answers to the three questions. In the original PUQE index, these questions ask how many times the patient has felt nauseous or nauseous, vomited, and retching or dry blistering in the past 12 hours. In a modified PUQE index, these symptoms were questioned for the past 24 hours. Scores from 1 to 5 were added for each question to determine the PUQE score. A patient's PUQE score can range from 4 to 15 . A PUQE score of $\leq 6$ is classified as a mild case of HEG, between 7 and 12 as moderate and $\geq 13$ as severe HEG [15-16]. The same scoring system was applied for the modified PUQE used in our study. Body mass index (BMI) $(\mathrm{kg} / \mathrm{m} 2)$ was obtained by dividing body weight $(\mathrm{kg})$ by height $(\mathrm{m} 2)$ squared. Gestational age was determined using the first day of the last month and confirmed by sonographic examination.

Exclusion criteria: Smoking, urinary tract infections, previously diagnosed psychological disorders, gastrointestinal disorders, multiple pregnancies, eating disorders, thyroid disorders, inflammatory disease, pregnancy with assisted fertilization technique.

From the medical records of the patients, HRR, ELR, NLR, PLR, PDW, MPV, PCT, White blood cell (WBC) count, Hemoglobin $(\mathrm{Hb})$, Platelet count number $(\mathrm{PLT})$ and ketonuria results were pooled.

\section{Statistical Analysis}

Statistical analysis was performed using SPSS version 22.0. Shapiro-Wilk test was used to assess whether the variables followed normal distribution or not. Variables were reported as mean (minimum: maximum) values. A Mann-Whitney $U$ test was used to compare patients in the Hyperemesis gravidarum (HEG) and control groups. Receiver operating characteristic (ROC) curve analysis was used to identify the optimal cut-off values of PCT, HRR, and, NLR for diagnosing severe HEG with maximum sensitivity and specificity. A Kruskal-Wallis test was performed to compare patients with mild, moderate, and severe HEG. Moreover, a Mann-Whitney U test was used for pair-wise comparison. A Spearman's correlation test was performed to determine whether there was a correlation between PCT, HRR, NLR, and HEG groups. To identify the independent risk factors affecting the development of HEG, binary logistic regression analysis was performed with the backward selection procedure. The level of significance was set at $a=0.05$.

\section{Results}

Demographic characteristics and laboratory findings of the patients are shown in Table 1. There was no significant difference between the HEG and control groups in terms of age, gestational age, parity BMI and thyroid functions $(p>0.05)$. WBC, HB, PCT, HRR, and NLR values were higher in the HEG group $(p>0.05)$.

Comparison of HEG subgroups according to laboratory values is summarized in Table 2. There is a significant difference between the groups according to PCT, HRR, and NLR values. According to PCT, HRR, and NLR values, there is a significant difference between the severe group and the mild and moderate 
group. There was no significant difference between the mild group and the moderate group. PCT, HRR, and NLR values increase from mild to severe groups.

The correlation between HEG and PCT, HRR, NLR values are shown in Table 3. There was a positive correlation between HEG and PCT (rho=0.70, p< 0.001), HRR (rho=0.28, $p<0.04), \operatorname{NLR}($ rho $=0.60, p<0.001)$ values

The effect of PCT, HRR, and NLR in the diagnosis of severe HEG was determined by the ROC curve (Fig. 1). ROC analysis results of inflammatory markers are shown in Table 4. Areas under the curve for PCT, HRR, and NLR were $0.80,0.76$, and 0.71 , respectively. $P C T>0.29, H R R>1.03$, and NLR> 4.93 were significantly associated with an increased risk of severe HEG $(p<0.05)$.

Logistic regression analysis revealed that a one-unit increase in PCT, HRR, and NLR resulted in a 2.14, 1.41, and 2.36-fold increase in HEG risk, respectively (Table 5).

\section{Discussion}

Hyperemesis gravidarum (HEG) is a condition that causes severe nausea and vomiting in early pregnancy and often requires hospitalization. HEG has a pathophysiological mechanism due to many causes [17]. Inflammation has a critical role in HEG. It has been reported that CRP levels increase in women with HEG. In addition, it was stated that the increase in CRP indicates the effectiveness of the inflammatory state and may contribute to the pathophysiology of HEG [18]. HEG may be severe enough to require hospitalization. It may even progress to central pontine myelinolysis and Wernicke's encephalopathy. Therefore, early diagnosis and treatment of HEG are very important for maternal and child health [19].

Although the link between HEG and inflammation is not fully understood, studies on markers of inflammation in HEG patients suggest a strong association between them $[8,20]$. In a study in the literature, no difference was observed in WBC counts between HEG patients and the control group [21]. HEG patients are expected to develop hemoconcentration due to vomiting and dehydration. Hemoglobin and white blood count (WBC) values were not different from the control group in the study by Bulanık et al. [22]. Unlike these studies, in our study, WBC values were found to be higher in the HEG group than in the control group $(p<0.05)$.

PCT, an inflammatory marker obtained from complete blood count, has been reported to have prognostic and predictive properties in various diseases such as gynecological and gastrointestinal malignancies, autoimmune diseases, and coronary artery diseases [23-24]. There are not many studies on the relationship between PCT and HEG. In the study by Tayfur et al., PCT values were found to be higher in women with HEG. In the same study, mild, moderate, and severe HEG cases were compared, and it was reported that PCT values were higher in severe HEG cases [25]. In our study, PCT values in the HEG group were found to be significantly higher than in the control group. In addition, mild, moderate, and severe HEG cases were compared and PCT values increased as one went from the mild group to the severe group. There was a positive correlation between HEG and PCT (rho $=0.70, p<0.001)$. According to the 
ROC analysis result; The rate of PCT $>0.29$ was determined statistically, and this parameter was significantly associated with an increased risk of severe HEG disease. Logistic regression analysis revealed that a one-unit increase in PCT resulted in a 2.14-fold increase in HEG risk.

It is reported that HRR alone is a stronger prognostic indicator than $\mathrm{Hb}$ or RDW. As the reason for this, it is thought that combining the prognostic information from Hemoglobin and RDW by HRR will provide more information than a single variable [14]. HRR is a recently used inflammatory marker derived from $\mathrm{Hb}$ and $\mathrm{RDW}$, which are complete blood count parameters used in routine practice. In addition, it has been shown to be a bad prognostic factor alone in many cancers such as stomach cancer and lung cancer [26-27]. Cintesun et al. found no significant difference in RDW between the HEG and control groups in their study [28]. Similarly, in our study, no significant difference was observed between the control and HEG groups in terms of RDW. There is no study in the literature about HRR in patients with hyperemesis gravidarum. We believe that the data we obtained in this study will lay the groundwork for future studies. In our study, HRR levels were found to be significantly higher in the HEG group than in the control group. When HEG subgroups are examined, HRR values increase significantly from mild to severe. There was a positive correlation between HEG and HRR (rho $=0.28, p<0.04$ ). According to the ROC analysis result; The rate of HRR $>1.03$ was determined statistically, and this parameter was significantly associated with an increased risk of severe HEG disease. Logistic regression analysis revealed that a one-unit increase in HRR resulted in a 1.41-fold increase in HEG risk.

NLR is used as an important marker in many diseases such as Diabetes Mellitus, kidney failure, heart diseases, inflammatory diseases, autoimmune diseases and hypertensive disorders [29]. NLR has been reported to increase gastrointestinal diseases, gynecological diseases, malignancies, heart diseases, and inflammation [30-31]. Looking at the literature, there are few studies on the severity of NLR and HEG. Soysal et al. reported that NLR levels were higher in the patient group. In the same study, a significant correlation was found between increased levels of ketonuria and NLR [32]. In another study, NLR levels were found to be high in HEG patients. However, no correlation was found between NLR values and the degree of ketonuria [21]. In the study by Kan et al., NLR levels were found to be higher in the HEG group. However, no correlation was found between the severity of the disease and NLR values [33]. In another similar study, a significant correlation was found between NLR levels and HEG groups [7].

In our study, NLR values were found to be higher in the HEG group. NLR values increase as one moves from the light group to the severe group. There was a positive correlation between HEG and NLR (rho = $0.60, p<0.001)$ values. According to the ROC analysis result; The rate of NLR $>4.93$ was determined statistically, and this parameter was significantly associated with an increased risk of severe HEG disease. Logistic regression analysis revealed that a one-unit increase in NLR resulted in a 2.36-fold increase in HEG risk.

Limitations of this study: First, the patient data were single-center, the number of patients was not large, and it was a retrospective study. Second, only HRR, PLR, NLR, ELR, MLR, and other hematological 
parameters are used as inflammatory markers. The strength of our study is that it is the first study to show the association of HRR with HEG.

\section{Conclusion}

PCT, HRR and NLR are inflammatory markers that increase in patients with HEG and have predictive value for the development of HEG. In our study, we suggested using the Hb/RDW ratio as a new prognostic marker for patients with HEG. HRR, PCT and NLR can be implemented at no additional cost. Since the relationship of HRR with HEG has not been definitively investigated, we cannot make a definitive statement about its clinical use yet. As more data on HRR levels are collected, HRR may be a marker of HEG. We think that our study will be a source for future studies on the subject.

\section{Declarations}

Conflict of interest The author disclosed no conflict of interest during the preparation or publication of this manuscript.

Financing The author disclosed that they did not receive any grant during conduction or writing of this study.

Author Contribution BAŞKIRAN Y: Project development, Data collection and management, Data analysis, Manuscript writing and editing.ÇELEĞEN I: Project development, Data collection and management, Data analysis, Manuscript writing and editing. UÇKAN K: Project development, Data collection and management, Data analysis, Manuscript writing and editing.

Ethics approval This study was conducted in line with the principles of the Declaration of Helsinki. Ethics committee approval was obtained for the study from the Van Ministry of Health University Training and Research Hospital Clinical Research and Ethics Committee with the decision number 2022/02-01 dated 18.01.2022.

Informed consent Informed consents were obtained from the study participants.

\section{References}

1: Ayyavoo A, Derraik JG, Hofman PL, Cutfield WS. (2014) Hyperemesis gravidarum and long-term health of the off spring. Am J ObstetGynecol. 210:521-5

2: Bashiri A, Neumann L, Maymon E, Katz M. (1995). Hyperemesis gravidarum: epidemiologic features, complications and outcome. European Journal of Obstetrics \& Gynecology and Reproductive Biology, 63(2), 135-138.

3: Eliakim R, Ovadia A, David MS. (2000) "Hyperemesis gravidarum: a current review." American journal of perinatology 17.04; 207-218. 
4: London V, Grube S, Sherer DM, Abulafia O. (2017). Hyperemesis gravidarum: a review of recent literature. Pharmacology, 100(3-4), 161-171.

5: Niemeijer MN, Grooten IJ, Vos N, Bais JM, Van Der Post JA, Mol BW et al. (2014). Diagnostic markers for hyperemesis gravidarum: a systematic review and metaanalysis. American journal of obstetrics and gynecology, 211(2), 150-e1.

6: Fell DB, Dodds L, Joseph KS, Allen VM, Butler B. (2006) Risk factors for hyperemesis gravidarum requiring hospital admission during pregnancy. Obstet Gynecol 107: 277-284

7: Kurt RK, Güler A, Silfeler DB, Ozçil MD, Karateke A, Hakverdi AU, et al. (2014) Relation of inflammatory markers with both presence and severity of hyperemesis gravidarum. Ginekol Pol. 85:589-93

8: Caglayan EK, Engin-Ustun Y, Gocmen AY, Sarı N, Seckin L, Kara M, et al. (2016) Is there any relationship between serum sirtuin-1 level and neutrophil-lymphocyte ratio in hyperemesis gravidarum? $\mathrm{J}$ Perinat Med. 44:315-20

9: Yildirim M, Turkyilmaz E, Avsar AF. (2015) Preoperative neutrophil-to-lymphocyte ratio has a better predictive capacity in diagnosing tubo-ovarian abscess. Gynecol Obstet Invest. 80:234-9

10: Torun S, Tunc BD, Suvak B, Yildiz H, Tas A, Sayilir A, et al. (2012) Assessment of neutrophillymphocyte ratio in ulcerative colitis: A promising marker in predicting disease severity. ClinRes Hepatol Gastroenterol. 36:491-7.

11: Weiss G. (2015) Anemia of chronic disorders: New diagnostic tools and new treatment strategies. Semin Hematol. 52:313-20

12: Patel KV, Semba RD, Ferrucci L, Newman AB, Fried LP, Wallace RB et al. (2010) Red cell distribution width and mortality in older adults: A meta-analysis. J. Gerontol. A Biol. Sci. Med. Sci. 65, 258-265.

13: Yeh, H.C.; Chien, T.M.; Wu, W.J.; Li, C.C.; Li, W.M.; Ke, H.L. et al. (2016) Is preoperativ anemia a risk factor for upper tract urothelial carcinoma following radical nephroureterectomy? Urol. Oncol. 34, 337.e1-337.e9.

14: Sun P, Zhang F, Chen C, Bi X, Yang H, An X et al. (2016) Theratio of hemoglobin to red cell distribution width as a novel prognostic parameter in esophageal squamous cell carcinoma: A retrospective study from southern China. Onco target 7, 42650

15: Koren G, Boskovic R, Hard M, Maltepe C, Navioz Y, Einarson A. (2002) Motherisk-PUQE (pregnancyunique quantification of emesis and nausea) scoring system for nausea and vomiting of pregnancy. Am J ObstetGynecol 186: 228-231. 
16. Lacasse A, Rey E, Ferreira E, Morin C, Berard A. (2008) Validity of a modified Pregnancy-Unique Quantification of Emesis and Nausea (PUQE) scoring index to assess severity of nausea and vomiting of pregnancy. Am J Obstet Gynecol 198: 71.

17: Verberg MF, Gillott DJ, Al-Fardan N, Grudzinskas JG. (2005) Hyperemesis gravidarum, a literature review. Hum Reprod Update. 2005 Sep-Oct;11(5):527-39

18: Engin-Ustun Y, Tonguç E, Var T, Deveer R, Yilmaz N, Danisman N et al. (2013) Vaspin and C-reactive protein levels in hyperemesis gravidarum. Eur Rev Med Pharmacol Sci. Jan;17(1):138-40".

19: Netravathi M, Sinha S, Taly AB, Bindu PS, Bharath RD. (2009) Hyperemesis-gravidarum-induced Wernicke'sencephalopathy: Serial clinical, electrophysiological and MR imaging observations. J NeurolSci ;284:214-6.

20: Tunc SY, Agacayak E, Budak S, Tunc N, Icen MS, Findik FM et al. (2016) Serum levels of neopterin, inflammatory markers and oxidative stress indicators in hyperemesis gravidarum. J Obstet Gynaecol Res. Jun;42(6):618-24

21: Çintesun E, Akar S, Gul A, Çintesun FNI, Sahin G, Ezveci H, et al. (2019)

Subclinicalinflammationmarkers in hyperemesisgravidarumandketonuria: a case-controlstudy. J LabPhysicians. 11:149-53

22: Bulanık M, Sağsöz N, Sayan CD, Yeral Mi, Kısa Ü. (2019) Comparison of Serum Ykl-40 and Ischemia Modified Albulmin Levels Between Pregnant Women with Hyperemesis Gravidarum and Normal Pregnant Women. Med Arch. 73(2):97-100

23: Viana-Rojas JA, Rosas-CabralA, Prieto-Macías J, Terrones-Saldívar MC, Arcos-Noguez P,

Bermúdez-Gómez J, et al. (2017) Relation of red cell distribution width and mean platelet volüme with the severity of preeclampsia. RevMedInstMexSeguroSoc. 55:176-81.

24. Zhao T, Cui L, Li A. (2016) The significance of RDW in patients with hepatocellular carcinoma after radical resection. Cancer Biomark. 16:507-12.

25: Tayfur C, Burcu DC, Gulten O, Betul D, Tugberk G, Onur O, et al. (2017) Association between platelet to lymphocyte ratio, platelet crit and the presence and severity of hyperemesis gravidarum. J Obstet Gynae col Res. 43:498-504

30: Kim DS, Shin D, Jee H, Kim TG, Kim SH, Kim DY et al (2015) Red blood cell distribution width is increased in patients with psoriasis vulgaris: a retrospective study on 261 patients. J Dermatol 42(6):567-571

26: Wu F, Yang S, Tang X, Liu W, Chen H, Gao H. (2020) Prognostic value of baseline hemoglobin-to-red blood cell distribution width ratio in small cell lung cancer: A retrospective analysis. Thorac Cancer. 11(4), 888-897. 
27: Yılmaz A, Mirili C, Tekin SB, Bilici M. (2020). The ratio of hemoglobin to red cell distribution width predict ssurvival in patients with gastric cancer treated by neo adjuvant FLOT: A retrospective study. Irish J. Med. Sci. 189, 91-102.

28: Akar S, Gul A, Çintesun FNI, Sahin G, Ezveci H, Akyürek F. et al. (2019). Subclinical inflammation markers in hyperemesis gravidarum and ketonuria: A case-control study. Journal of laboratory physicians, 11(02), 149-153.

29: Ilhan M, Ilhan G, Gok AF, Bademler S, Verit Atmaca F, Ertekin C. (2016) Evaluation of neutrophillymphocyte ratio, platelet-lymphocyte ratio and red blood cell distribution width- platelet ratio as early predictor of acute pancreatitis in pregnancy. J Matern Fetal Neonatal Med. 29: 1476-1480

30: Emektar E, Çorbacıoğlu ŞK, Dağar S, Uzun osmanoğlu H, Şafak T, Çevik Y. (2017) Prognostic Value of the Neutrophil-Lymphocyte and Platelet-Lymphocyte Ratios in Predicting One-Year Mortality in Patients with Hip Fractures and Aged Over 60 Years. Eurasian J Emerg Med. 16:165-70.

31. Akpinar MY, Ozin YO, Kaplan M, Ates I, Kalkan IH, Kilic ZMY et al. (2018). Platelet-to-lymphocyte ratio and neutrophil-to-lymphocyte ratio predict mucosal disease severity in ulcerative colitis. Journal of medical biochemistry, 37(2), 155.

32: Soysal C, Işık alan MM, Bıyık I, Erten Ö, İnce O.

(2021) The relationship between inflammation markers and ketonuria in hyperemesis gravidarum.J Obstet Gynaecol Res. Sep;47(9):3078-3083

33: Kan E, Emektar E, Corbacioglu K, Safak T, Sariaydin T, Cevik Y. (2020) Evaluation of relationship between inflammatory markers and hyperemesis gravidarum in patients admitted to emergency department. Am J Emerg Med.38:292-5

\section{Tables}


Table 1. Comparison of demographic and the laboratory parameters between the groups.

\begin{tabular}{|c|c|c|c|c|c|}
\hline \multirow[b]{2}{*}{ Age } & \multicolumn{2}{|c|}{$\begin{array}{l}\text { Control group } \\
\qquad(\mathrm{n}=113)\end{array}$} & \multicolumn{2}{|c|}{$\begin{array}{l}\text { HEG group } \\
\qquad(\mathrm{n}=102)\end{array}$} & \multirow[b]{2}{*}{ 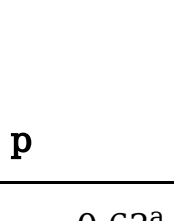 } \\
\hline & 29.49 & $(18.00-42.00)$ & 29.89 & $(18-42)$ & \\
\hline Gravida & 1 & $(1-4)$ & 1 & $(1-4)$ & $0.67^{\mathrm{a}}$ \\
\hline Gestational age (week) & 10.53 & $(7-12)$ & 10.34 & $(7.00-12)$ & $0.43^{\mathrm{a}}$ \\
\hline Parity (number) & 1 & $(0: 5)$ & 1 & $(0: 5)$ & $0.30^{\mathrm{a}}$ \\
\hline Body mass index $(\mathrm{kg} / \mathrm{m} 2)$ & 26.70 & $(22.10-30.10)$ & 26.30 & $(22.10-30.20)$ & $0.17^{\mathrm{a}}$ \\
\hline TSH (U/L) & 0.32 & $0.28-3.6$ & 0.31 & $0.29-3.4$ & $0.23^{\mathrm{a}}$ \\
\hline fT4 (pmol/L) & 13.43 & $13-18$ & 13.39 & $12-19$ & $0.34^{\mathrm{a}}$ \\
\hline WBC & 6.53 & $(5.30-8.20)$ & 9.79 & $(4.73-15.80)$ & $0.001^{\mathrm{a}}$ \\
\hline $\mathrm{HB}(\mathrm{g} / \mathrm{dl})$ & 12.93 & \pm 1.06 & 13.47 & \pm 1.19 & $0.001^{b}$ \\
\hline MCV & 92.22 & $(90.50-96.00)$ & 92.30 & (83.10-99.70) & $0.64^{\mathrm{a}}$ \\
\hline $\operatorname{PLT}\left(10^{3} / \mu \mathrm{l}\right)$ & 265.63 & $(195-355)$ & 271.48 & $(166-409)$ & $0.48^{\mathrm{a}}$ \\
\hline РCT(\%) & 0.23 & $(0.16-0.23)$ & 0.31 & $(0.17-0.58)$ & $0.001^{\mathrm{a}}$ \\
\hline RDW(\%) & 16.49 & $(16.10-16.50)$ & 16.47 & $(11.7-16.90)$ & $0.43^{\mathrm{a}}$ \\
\hline MPV(fl) & 9.20 & \pm 0.42 & 9.17 & \pm 0.95 & $0.23^{b}$ \\
\hline HRR(\%) & 0.98 & $(0.79-1.17)$ & 1.0063 & $(0.66-1.27)$ & $0.04^{\mathrm{a}}$ \\
\hline PLR(\%) & 182.19 & $(62.10-581.97)$ & 187.04 & $(54.43-670.50)$ & $0.07^{\mathrm{a}}$ \\
\hline NLR(\%) & 2.88 & $(0.42-8.07)$ & 5.43 & $(1.15-21.8)$ & $0.001^{\mathrm{a}}$ \\
\hline MLR(\%) & 0.26 & $(0.06-0.56)$ & 0.27 & $(0.12-1.03)$ & $0.15^{\mathrm{a}}$ \\
\hline ELR(\%) & 0.05 & $(0.001-0.32)$ & 0.04 & $(0.01-0.29)$ & $0.09^{\mathrm{a}}$ \\
\hline
\end{tabular}

The levels of categories are presented as the mean standard deviation for parametric variables and median 
(min-max) for nonparametric variables. Values in bold represent statistically significant out comes.; Abbreviations: Thyroid Stimulating Hormone (TSH), free T4 (fT4), WBC; White Blood Cell, Hb; hemoglobin, MCV; mean corpuscular volüme, PLT; platelet count, PCT; platelet crit, RDW; red cell distribution width, MPV; mean platelet volüme; HRR; Hemoglobin to red cell distribution width ratio, , PLR: platelet to lymphocyte ratio, NLR: neutrophil to lymphocyte ratio, MLR: monocytes to lymphocyte ratio, ELR: eosinophil to lymphocyte ratio. a Mann-Whitney $\mathrm{U}$ test, and b independent sample t test

Table 2. Comparison of the Laboratory parameters of mild, moderate, and severe HEG groups.

\begin{tabular}{lcccc}
\hline & $\begin{array}{c}\text { Mild } \\
(\mathbf{n}=\mathbf{3 8})\end{array}$ & $\begin{array}{c}\text { Moderate } \\
(\mathbf{n = 3 2})\end{array}$ & $\begin{array}{c}\text { Severe } \\
(\mathbf{n = 3 2})\end{array}$ & $\mathbf{p}$ \\
\hline PCT(\%) & $0.26(0.17-0.43)$ & $0.27(0.23-0.54)$ & $0.37(0.23-0.58)$ & $\mathbf{0 . 0 0 1}$ \\
HRR(\%) & $0.96(0.71-1.18)$ & $0.98(0.72-1.23)$ & $1.09(0.82-1.35)$ & $\mathbf{0 . 0 0 1}$ \\
NLR(\%) & $3.94(1.15-7.91)$ & $5.40(7.26-8.62)$ & $7.09(2.67-21.18)$ & $\mathbf{0 . 0 0 1}$ \\
\hline
\end{tabular}

Values are expressed as mean and inter quartile ratios (IQR) 25-75\%. PCT; platelet crit; HRR; Hemoglobin to red cell distribution width ratio,, NLR: neutrophil to-lymphocyte ratio, Bold $\mathrm{p}$ values indicate statistically significant.

Table 3. Correlation between Hyperemesis gravidarum and PCT, HRR, NLR.

\begin{tabular}{ccc}
\hline & $\mathbf{R}$ & $\mathbf{P}$ \\
\hline PCT & 0.70 & $\mathbf{0 . 0 0 1}$ \\
HRR & 0.28 & $\mathbf{0 . 0 4}$ \\
NLR & 0.60 & $\mathbf{0 . 0 0 1}$ \\
\hline
\end{tabular}

Abbreviations: PCT; platelet crit, HRR; Hemoglobin to red cell distribution width ratio, NLR: neutrophil to lymphocyte ratio. Bold p values indicate statistically significant. 
Table 4. Roc analysis results for inflammatory variables

\begin{tabular}{lllllll}
\hline Variables AUC & SE & $p$ & Predictive value & Sensitivity & Specificity & 95\% Confidence interval
\end{tabular}

\begin{tabular}{lllllllll}
\hline PCT & 0.80 & 0.47 & $\mathbf{0 . 0 0 1}$ & 0.29 & 0.78 & 0.72 & 0.71 & 0.89 \\
HRR & 0.76 & 0.51 & $\mathbf{0 . 0 0 1}$ & 1.03 & 0.75 & 0.74 & 0.67 & 0.86 \\
\hline NLR & 0.71 & 0.57 & $\mathbf{0 . 0 0 1}$ & 4.93 & 0.71 & 0.60 & .60 & 0.82
\end{tabular}

Abbreviations: AUC; Area under the curve, SE; Standart eror, PCT; platelet crit, HRR; Hemoglobin to red cell distribution width ratio, NLR: neutrophil to lymphocyte ratio. Bold p values indicate statistically significant.

Table 5. The effects of PCT, HRR and NLR on HEG development by binary logistic regression analysis

\begin{tabular}{lcccc}
\hline & B & OR & 95\% C. I & p \\
\hline PCT & 0.76 & 2.14 & $1.65-2.79$ & $\mathbf{0 . 0 0 1}$ \\
HRR & 0.34 & 1.41 & $1.12-1.76$ & $\mathbf{0 . 0 3}$ \\
NLR & 0.863 & 2.36 & $1.66-3.36$ & $\mathbf{0 . 0 0 1}$ \\
\hline
\end{tabular}

Abbreviations: PCT; Platelet crit, Hemoglobin to red cell distribution width ratio (HRR), NLR: neutrophil-tolymphocyte ratio, Bold $\mathrm{p}$ values indicate statistically significant.

\section{Figures}




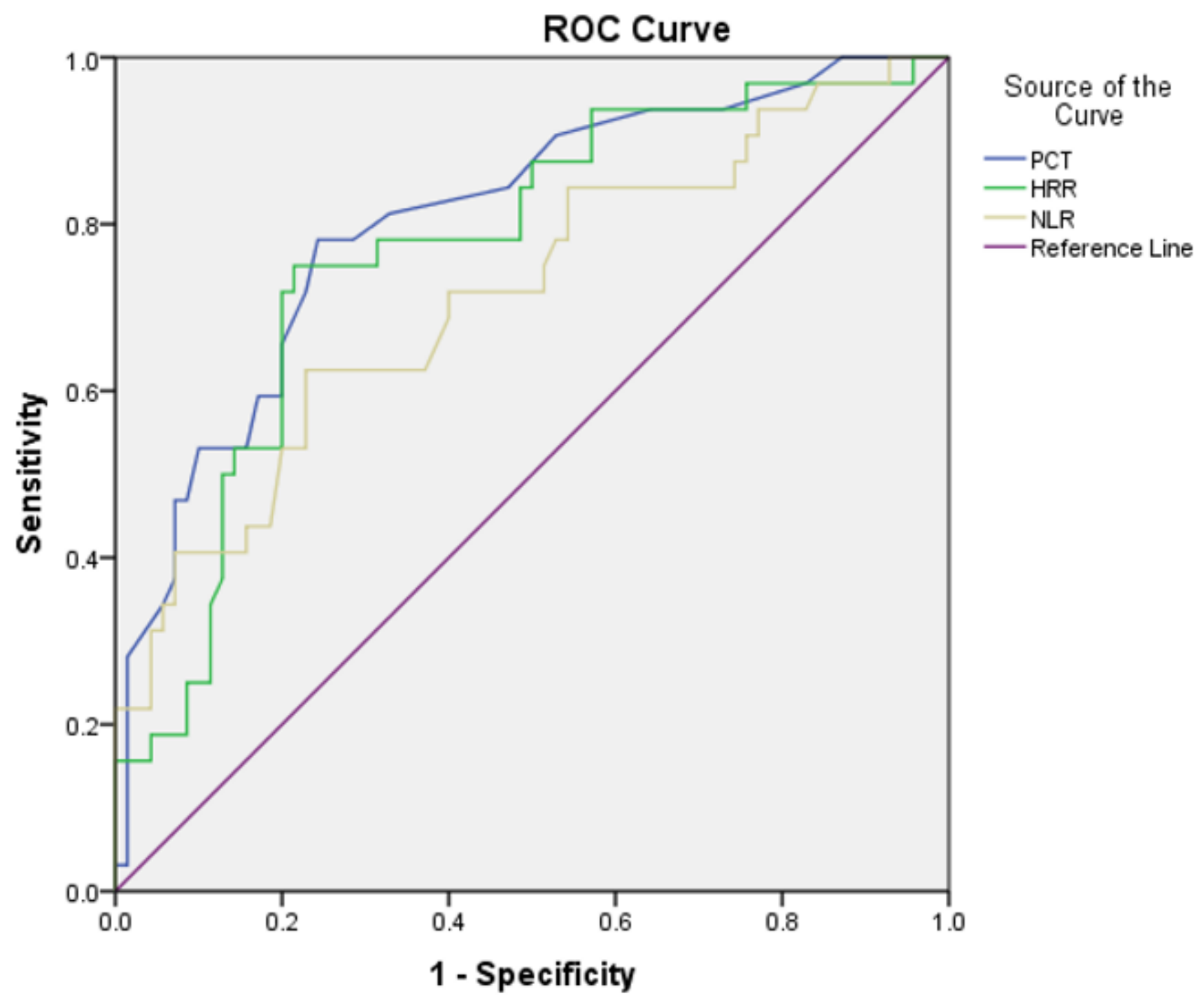

Figure 1

Receiver operating characteristic curves hemoglobin to red cell distribution width ratio (HRR), neutrophillymphocyte ratio (NLR), and platelet crit (PCT) for the diagnosis of severe hyperemesis gravidarum. 